\title{
EATING DISORDERS WITH FEMALE ATHLETES: IMPORTANCE OF THE KIND OF SPORT AND LEVEL OF PARTICIPATION
}

\author{
Diana Dimitrova, Galina Vanlyan \\ National Sports Academy "Vassil Levski", Sofia, Bulgaria
}

\begin{abstract}
Introduction: There is still conflicting information about the prevalence of EDs with female athletes. The results for different countries and subpopulations of athletes also show large variations due to various reasons including intercultural differences, eating habits and behaviors.

Purpose: The aim of this first for Bulgaria study was to examine the prevalence of eating disorder attitudes and behaviors among Bulgarian female athletes and to estimate how eating disorders vary across the nature of the sport and level of proficiency.

Methods: A total of 363 female athletes, aged between 12-25 years participated in the study. All participants completed an anonymous paper-based EDE-Q and provided information about their age, sports experience, participation in competitions and competitive level.

The subjects were divided into groups according to the type of sport (aesthetic and non-aesthetic) and level of participation (non-competitive, low and high competitive level).

Results: There were no differences between the athletes in the subgroups with respect to any of the $E D E-Q$ subscales. On the basis of pre-established cutoff score of 4 on EDE-Q scales and the presence of pathological eating behavior we found the same prevalence rate of eating disorder with female athletes in both aesthetic sports (33.3\%) and non-aesthetic sports (31.8\%). Although the tendency of increasing the incidents with DE was observed, the statistical analysis showed no significant differences between the three groups with respect to the level of participation.

Conclusion: This study found a relatively high prevalence of abnormal eating patterns with Bulgarian female athletes, as measured by EDE-Q. Eating disorder behavior is a prerequisite for increased risk of mental eating disorders and serious health problems.
\end{abstract}

Key words: disorder eating, female athletes, $E D E-Q$, prevalence rate

\section{INTRODUCTION}

In recent years the syndrome of Female athlete triad has come into public view, because it is a potentially serious condition that significantly impairs the physical health or psychosocial wellbeing of athletes. Female athlete triad consists of three interrelated components - eating disorders, menstrual irregularities and low bone density. In the last Consensus Statement (2014) each of the three components is defined as a wide spectrum ranging from optimal condition to clinical manifested disease (De Souza, et al., 2014).
According to current concepts the initiating and causative factor for the triad is the low energy availability, which in turn affects the menstrual function and bone density through a cascade of events. Most often the energy deficit is due to the wide spectrum of abnormal eating attitudes, which range in severity. Desiring to enhance their performance, to achieve or maintain unrealistically low weight or to achieve a lean appearance some females engage in pathogenic weight-control behaviors such as frequently skipping meals, fasting and starvation, binge-eating followed by purging, 
use of weight loss pills, laxatives, diuretics, excessive exercise. These pathological eating behaviors often have sub-clinical manifestations and do not meet the clinical diagnostic criteria for mental disorders (anorexia nervosa, bulimia nervosa and binge eating disorder) and are classified as other specified feeding or eating disorders (OSFEDs) in Diagnostic and Statistical Manual of Mental Disorders: Fifth Edition (DSM-5).

In the last decade, a number of studies have found, that athletic population is at higher risk of eating disorders (EDs) than the general population (Byrne, McLean, 2002; Beals, Hill, 2006; Nichols et al., 2006, 2007; Pernick at al., 2006; Sundgot-Borgen, 1993; Torstveit et al., 2007) Athletes are more susceptible to EDs because they are more obsessive about their weight and are highly motivated to diet in order to improve their performance and physical appearance. Although numerous studies reported eating disturbances to be more prevalent among female athletes, data are not quite unambiguous, because some authors did not establish significant differences between athletes and non-athletes (Ashley et al., 1996; Thompson, Gabriel, 2004) or even found higher prevalence among the controls (Rosendahl et al., 2009; Martinsen et al., 2010).

Due to heterogeneity of study samples of athletes there is still conflicting information about the prevalence of EDs with respect to the nature of the sport and competitive level. It is suggested there is higher prevalence among athletes in sports that promote leanness for performance or aesthetic reasons. The subjective evaluation and the strive to achieve "ideal body type" make athletes susceptible to the development of Eds (Harris, Greco, 1990; Rosen, Hough, 1988; Sundgot-Borgen, 1994, 1996; Sundgot-Borgen, Corbin, 1987; Sundgot-Borgen, Larsen, 1993.

Some authors found increased risk of EDs among elite athletes, as compared to recreational and lower competitive level athletes
(Picard, 1999; Johnson et al., 1999).

The results for different countries and subpopulations also show large variations due to various reasons including intercultural differences, eating habits and behaviors (Welch et al., 2011).

Various psychometric measures are used for assessment of the severity and specific types of DE behaviors among athletes. Among questionnaires used Eating Disorder Examination Questionnaire (EDE-Q) is considered the gold standard for assessment of the eating disturbances among different population and subpopulation groups. Its criterion validity has been reported by numerous authors (Lavender et al., 2010; Luce et al., 2008; Mond et al., 2008).

The aim of this first for Bulgaria study was to examine by the means of EDE-Q (1) the prevalence of eating disorder (DE) attitudes and behaviors among Bulgarian female athletes and (2) to estimate how eating disorders vary across the nature of the sport and level of proficiency.

\section{MATERIALS \& METHODS \\ Subjects}

The subject sample consisted of 363 female athletes. 206 of them (between 19 and 25 years old) were students at the National Sports Academy of Sofia. Additionally, 157 female students (aged between 12 and 18 years attending the Secondary Sports School) participated in the survey.

Informed consent was obtained from all subjects or their parents. The participants were also asked to provide information about their age, sports experience, participation in competitions and competitive level. BMI was calculated based on participant's data for height and weight.

For the purposes of the study, we divided the subjects into groups according to the type of sport and level of participation.

Depending of the type of sport, 2 sub- 
groups were formed - aesthetic and non-aesthetic sports. The current study defined the aesthetic sports as sports (1) which place emphasis on the body appearance and (2) success depends on judge's subjective evaluation. In this group we included 99 female athletes in the following sports: rhythmic gymnastics 50 ; artistic gymnastics - 5; aerobic gymnastics - 10; sports acrobatics - 9; dance sport 24 , figure skating -1 . The non-aesthetic sports group consisted of 264 athletes in the following sports: ball games -85 , racket sports -16 , track and field -23 , combat sports -24 , winter and ice sports -16 , rowing -12 , cycling 6 , swimming -17 , fitness -45 , shooting -14 , fencing -6 .

The female athletes were also categorized in three groups with respect to the level of athletic participation as follows:

Noncompetitive athletes/exercisers (NC) recreational athletes engaged in regular sports activities at least twice weekly without participating in competitions.

Low competitive level (LCL) - non-elite athletes engaged in regular sports and competing on regional and national level.

High competitive level (HCL) - elite athletes engaged in regular trainings and participating in international competitions.

This research received approval from Ethical board of National Sports Academy in Sofia.

\section{Screening for eating disorders}

All athletes completed an anonymous paper-based EDE-Q (Fairburn, Beglin, 2008)

EDE-Q is a 28-item self-report instrument, which assesses the eating disorder attitudes by 4 subscales (restraint, eating concerns, weight concern and shape concern) and a global score, which is derived as an average of the score of the subscale scores. All items refer to the preceding 28 days, and frequency or intensity is rated on seven point Likert scale ranging from 0 (no days) to 6 (every day). Additionally, EDE-Q consists of 4 questions for screening of the following pathogenic behaviors: binge eating episodes, and self-induced vomiting, laxative misuse for controlling the body weight.

We used the following criteria to classify the female athletes with DE: (1) a cutoff score of 4.0 or greater; or (2) eating behavior like binge eating, self-induced vomiting and use of laxatives, which was practiced on $>2$ of the previous 28 days; or (3) excessive exercise for controlling the weight at least five times per week over the past 28 days.

\section{Statistical analysis}

Statistical analyses were performed with the use of SPSS-23. Descriptive statistics (mean \pm standard deviation) were computed for anthropometric measures as well as for EDE-Q subscale scores and for global score. Independent $t$-test was used to compare age and physical characteristics of the athletes in aesthetic and non-aesthetic sports and ANOVA statistics was used for evaluation of differences in the same parameters between the three groups according to competitive level. DE was reported as both a continuous and a dichotomous variable. The differences in EDEQ scores of the studied groups were examined by nonparametric tests Mann-Whitney U-test and Kruskal-Wallis test.

Chi-square analyses were conducted to compare differences in percentage of athletes with DE according to sport type and competitive level.

\section{RESULTS}

The descriptive analysis of the age and anthropometric characteristics of the studied groups according to sport type and level of athletic participation is presented in Table 1. 
Table 1. Subject characteristics (mean $\pm S D$ )

\begin{tabular}{lcccccc}
\hline \multicolumn{1}{c}{ Groups } & N & Age (years) & $\begin{array}{c}\text { Sports } \\
\text { experience }\end{array}$ & Height $(\mathbf{c m})$ & Weight $(\mathbf{k g})$ & BMI $\left(\mathbf{k g} / \mathbf{m}^{2}\right)$ \\
\hline Aesthetic sports & 99 & $18,57 \pm 3,77$ & $9,70 \pm 4,32$ & $164,04 \pm 6,27 * *$ & $50,38 \pm 7,85^{* *}$ & $18,86 \pm 2,35^{*}$ \\
Other sports & 264 & $18,75 \pm 3,07$ & $6,55 \pm 3,93$ & $168,25 \pm 8,55$ & $58,84 \pm 8,59$ & $19,69 \pm 5,05$ \\
NC athletes & 47 & $20,53 \pm 2,31^{* *}$ & $5,59 \pm 5,02$ & $167,04 \pm 8,77$ & $56,30 \pm 7,36^{*}$ & $20,19 \pm 2,38^{*}$ \\
LCL athletes & 215 & $18,12 \pm 3,41$ & $8,14 \pm 3,97$ & $166,82 \pm 8,52$ & $55,66 \pm 9,67$ & $19,91 \pm 2,47$ \\
HCL athletes & 101 & $19,09 \pm 2,99$ & $9,37 \pm 3,77$ & $167,73 \pm 7,16$ & $58,49 \pm 8,71$ & $20,73 \pm 2,31$ \\
\hline${ }^{*} \mathrm{p}<0.05 ;{ }^{* *} \mathrm{p}<0.01$ & & & & &
\end{tabular}

The comparison showed that the female athletes from aesthetic sports are, on average, shorter and lighter than sportswomen from the other sports. The BMI was also lower in aesthetic sports group.

No differences in height were observed when compared athletes, according to their competitive level (recreational, non-elite and elite athletes), but the noncompetitive athletes are significantly older, heavier and with higher BMI than the other two groups.
Table 2 summarizes the mean scores of EDE-Q of the examined groups. There were no differences between the athletes in the subgroups with respect to any of the EDE-Q subscales. The mean scores of EDE-Q scales varied between: 1.22-1.72 for "Restraint" subscale, 0.59-0.84 for "Eating concern" subscale, 1.59-2.04 for "Shape concern" subscale, 1.46-1.81 for "Weight concern" subscale, 1.24-1.58 for "Global score".

Table 2. EDE-Q scores (mean $\pm S D$ )

\begin{tabular}{|c|c|c|c|c|c|}
\hline Groups & Restraint & $\begin{array}{c}\text { Eating } \\
\text { concern }\end{array}$ & $\begin{array}{c}\text { Shape } \\
\text { concern }\end{array}$ & $\begin{array}{c}\text { Weight } \\
\text { concern }\end{array}$ & $\begin{array}{c}\text { Global } \\
\text { score }\end{array}$ \\
\hline Aesthetic sports & $1,27 \pm 1,49$ & $0,81 \pm 1,11$ & $1,89 \pm 1,65$ & $1,63 \pm 1,41$ & $1,40 \pm 1,24$ \\
\hline Other sports & $1,43 \pm 1,39$ & $0,80 \pm 0,88$ & $1,89 \pm 1,47$ & $1,65 \pm 1,46$ & $1,44 \pm 1,12$ \\
\hline $\mathrm{NC}$ athletes & $1,22 \pm 1,38$ & $0,59 \pm 0,69$ & $1,59 \pm 1,40$ & $1,46 \pm 1,41$ & $1,24 \pm 1,04$ \\
\hline LCL athletes & $1,27 \pm 1,30$ & $0,83 \pm 0,95$ & $1,89 \pm 1,52$ & $1,61 \pm 1,44$ & $1,45 \pm 1,15$ \\
\hline HCL athletes & $1,72 \pm 1,63$ & $0,84 \pm 1,01$ & $2,04 \pm 1,55$ & $1,81 \pm 1,46$ & $1,58 \pm 1,24$ \\
\hline
\end{tabular}

The comparison showed that the female athletes from aesthetic sports are, on average, shorter and lighter than sportswomen from the other sports. The BMI was also lower in aesthetic sports group.

No differences in height were observed when compared athletes, according to their competitive level (recreational, non-elite and elite athletes), but the noncompetitive athletes are significantly older, heavier and with higher BMI than the other two groups.
Table 2 summarizes the mean scores of EDE$\mathrm{Q}$ of the examined groups. There were no differences between the athletes in the subgroups with respect to any of the EDE-Q subscales. The mean scores of EDE-Q scales varied between: 1.22-1.72 for "Restraint" subscale, 0.59-0.84 for "Eating concern" subscale, 1.59-2.04 for "Shape concern" subscale, 1.46-1.81 for "Weight concern" subscale, 1.24-1.58 for "Global score". 
Table 2. EDE-Q scores (mean $\pm S D$ )

\begin{tabular}{lccccc}
\hline \multicolumn{1}{c}{ Groups } & Restraint & $\begin{array}{c}\text { Eating } \\
\text { concern }\end{array}$ & $\begin{array}{c}\text { Shape } \\
\text { concern }\end{array}$ & $\begin{array}{c}\text { Weight } \\
\text { concern }\end{array}$ & $\begin{array}{c}\text { Global } \\
\text { score }\end{array}$ \\
\hline Aesthetic sports & $1,27 \pm 1,49$ & $0,81 \pm 1,11$ & $1,89 \pm 1,65$ & $1,63 \pm 1,41$ & $1,40 \pm 1,24$ \\
\hline Other sports & $1,43 \pm 1,39$ & $0,80 \pm 0,88$ & $1,89 \pm 1,47$ & $1,65 \pm 1,46$ & $1,44 \pm 1,12$ \\
\hline NC athletes & $1,22 \pm 1,38$ & $0,59 \pm 0,69$ & $1,59 \pm 1,40$ & $1,46 \pm 1,41$ & $1,24 \pm 1,04$ \\
\hline LCL athletes & $1,27 \pm 1,30$ & $0,83 \pm 0,95$ & $1,89 \pm 1,52$ & $1,61 \pm 1,44$ & $1,45 \pm 1,15$ \\
\hline HCL athletes & $1,72 \pm 1,63$ & $0,84 \pm 1,01$ & $2,04 \pm 1,55$ & $1,81 \pm 1,46$ & $1,58 \pm 1,24$ \\
\hline${ }^{*} \mathrm{p}<0.05 ;{ }^{* *} \mathrm{p}<0.01$ & & & & &
\end{tabular}

On the basis of pre-established cutoff score of 4 on EDE-Q scales and the presence of pathological eating behavior we found the same prevalence rate of disordered eating with female athletes in both aesthetic sports $(33.3 \%$, $\mathrm{n}=33)$ and non-aesthetic sports $(31.8 \%, \mathrm{n}=84)$ (table 3 ). Statistically significant differences in incidents of scores $\geq 4$ in subscales of the EDE-Q between both subgroups according to sports type were not detected, except the higher Global score in aesthetic sports. Global EDE-Q scores between 4 and 6 indicate eating disorder tendencies.

Regarding the pathological eating behaviors and exercise habits that are a prerequisite for a higher risk of eating disorders we found significantly higher prevalence rate only in self-induced vomiting in female athletes in aesthetic sports.

With respect to the level of participation there was a strong trend of increasing the percentage of sportswomen with a higher level of athleticism. The prevalence of EDE-Q scores $\geq 4$ or DE behaviors in the group of noncompetitive athletes was $21.3 \%$, in low competitive level athletes was $33.5 \%$ and in elite athletes was $34.6 \%$. Although the tendency of increasing the incidents with DE was observed, the statistical analysis showed no significant differences between the three groups in both the EDE-Q subscales and pathological behaviors.

Table 3. Proportions of female athletes with DE

\begin{tabular}{lccccc}
\hline \multirow{2}{*}{$\begin{array}{c}\text { EDE-Q subscales/ } \\
\text { pathogenic behaviors }\end{array}$} & $\begin{array}{c}\text { Aesthetic } \\
\text { sports } \\
(\mathbf{n}=\mathbf{9 9})\end{array}$ & $\begin{array}{c}\text { Other } \\
\text { sports } \\
(\mathbf{n}=\mathbf{2 6 4})\end{array}$ & $\begin{array}{c}\text { Level of athletic participation subgroups } \\
\text { athletes } \\
(\mathbf{n}=\mathbf{4 7})\end{array}$ & $\begin{array}{c}\text { LCL athletes } \\
(\mathbf{n}=\mathbf{2 1 5})\end{array}$ & $\begin{array}{c}\text { HCL } \\
\text { athletes } \\
(\mathbf{n}=\mathbf{1 0 1})\end{array}$ \\
\hline Restraint & $7.1 \%(\mathrm{n}=7)$ & $4.9 \%(\mathrm{n}=13)$ & $2.1 \%(\mathrm{n}=1)$ & $4.2 \%(\mathrm{n}=9)$ & $9.9 \%(\mathrm{n}=10)$ \\
\hline Shape concern & $18.2 \%(\mathrm{n}=18)$ & $11.4 \%(\mathrm{n}=30)$ & $8.5 \%(\mathrm{n}=4)$ & $12.6 \%(\mathrm{n}=27)$ & $16.8 \%(\mathrm{n}=17)$ \\
\hline Weight concern & $8.1 \%(\mathrm{n}=8)$ & $8.3 \%(\mathrm{n}=22)$ & $4.3 \%(\mathrm{n}=2)$ & $7.9 \%(\mathrm{n}=17)$ & $10.9 \%(\mathrm{n}=11)$ \\
\hline Global score & ${ }^{\star} .1 \%(\mathrm{n}=7)$ & $1.9 \%(\mathrm{n}=5)$ & $0 \%(\mathrm{n}=0)$ & $3.3 \%(\mathrm{n}=7)$ & $4.9 \%(\mathrm{n}=5)$ \\
\hline Binge eating & $28.3 \%(\mathrm{n}=28)$ & $37.5 \%(\mathrm{n}=99)$ & $34.0 \%(\mathrm{n}=16)$ & $35.4 \%(\mathrm{n}=76)$ & $34.6 \%(\mathrm{n}=35)$ \\
\hline Self-induced vomiting & ${ }^{\star} 4.0 \%(\mathrm{n}=4)$ & $0.7 \%(\mathrm{n}=2)$ & $2.1 \%(\mathrm{n}=1)$ & $1.4 \%(\mathrm{n}=3)$ & $1.9 \%(\mathrm{n}=2)$ \\
\hline Use of laxatives & $7.1 \%(\mathrm{n}=7)$ & $6.1 \%(\mathrm{n}=16)$ & $4.3 \%(\mathrm{n}=2)$ & $6.1 \%(\mathrm{n}=13)$ & $7.9 \%(\mathrm{n}=8)$ \\
\hline Excessive exercise & $15.2 \%(\mathrm{n}=15)$ & $23.1 \%(\mathrm{n}=61)$ & $14.9 \%(\mathrm{n}=7)$ & $22.8 \%(\mathrm{n}=49)$ & $19.8 \%(\mathrm{n}=20)$ \\
\hline Disordered eating ${ }^{a}$ & $33.3 \%(\mathrm{n}=33)$ & $31.8 \%(\mathrm{n}=84)$ & $21.3 \%(\mathrm{n}=10)$ & $33.5 \%(\mathrm{n}=72)$ & $34.6 \%(\mathrm{n}=35)$ \\
\hline a Mean score $\geq 4$ of Weight, Shape, or Restraint subscale or Global score; or reported pathogenic eating behavior on \\
$\geq 2$ d; or practicing excessive exercise $\geq 5 \mathrm{~d}$ in the past $28 \mathrm{~d} ;{ }^{*} \mathrm{p}<0.05$ & & &
\end{tabular}




\section{DISCUSSION}

These results are part of the first study on the prevalence of eating disorder symptoms among the athletic population in Bulgaria.

The mean values of the EDE-Q subscales and the Global score did not differ significantly between studied groups.

However, this study found that nearly onethird of the female athletes were experiencing eating disturbances and many of them had more than one symptomatic score.

In this sample between $0 \%$ and $10.9 \%$ of the female athletes scored in the clinically significant for disordered eating range on the Restraint, Weight concern and Global score scales. The exception is Shape concern with higher percentages ranged between $8.5 \%$ and $18.2 \%$. The Shape concern category measures the individual's fear of fat accumulation and weight gain, which is associated with dissatisfaction with body shape. Therefore, the high scores of this scale are not surprising not only for the athletes from aesthetic sports, but for all young women who are concerned about their appearance.

Regarding behavioral features, we identified a high percentage of female athletes with binge eating behaviors as consumption of an unusually large amount of food and a loss of control over eating $(28.3 \%$ - 37.5\%). Compared to the data for the general population $(15.5 \%)$, these results show a significantly higher incidence of this psychopathological eating behavior among athletes (Petrova et al., 2017).

The observed in this study higher incidents of DE in aesthetic sports in terms of Global score of EDE-Q and self-induced vomiting is consistent with higher rates of DE established for this athlete group by other authors (Smolak et al., 2000; Reinking, Alexander, 2005; West, 1998). Global EDE-Q scores between 4 and 6 indicate eating disorder tendencies.

The comparisons revealed that there were no group differences with respect to the ath- letic level of participation. These results are not consistent with the study of Thompson\& Gabriel (2004) who found higher prevalence of ED among non-competitive athletes as compared to competitive and with found by Picard (1999) more signs of pathological eating among athletes at higher levels of competition. Despite the lack of statistically significant differences in the prevalence rate of eating disorders among athletes from different levels of athleticism, there is a marked tendency of increase in the percentage with the level of proficiency.

This pilot study is limited by the fact that all participants were recruited from National

Sports Academy "V. Levski" and Secondary Sports School, where they were students at the moment of investigation. In addition, research has not taken into account the amount, type, and intensity of exercise performed from athletes.

\section{CONCLUSIONS}

This study found a relatively high prevalence of abnormal eating patterns among Bulgarian female athletes, as measured by EDEQ. Disordered eating behavior is a prerequisite for increased risk of mental eating disorders and serious health problems. Our data suggest a higher risk for susceptibility to developing eating disorders with female athletes in aesthetic sports. They have a higher percentage of scores in the clinically significant range on Global score of EDE-Q and the score obtained for self-induced vomiting is higher than in the other sports. Although, no differences were established between athletes at different levels of participation, we observed such a tendency. More research is needed to gain a deeper insight into the problem.

\section{ACKNOWLEDGMENTS}

This article is a result of research funded by the National Sports Academy "Vassil Levski". The funding institution had no role in the 
study design, collection, analysis or interpretation of data.

The authors thank the athletes participating in this study.

\section{REFERENCES}

American Psychiatric Association. Diagnostic and Statistical Manual of Mental Disorders (4th ed.). Washington, DC: American Psychiatric Association, 1994.

Ashley, C.D., Smith, J.F., Robinson, J.B., Richardson, M.T. (1996) Disordered eating in female collegiate athletes and collegiate females in an advanced program of study: a preliminary investigation. International Journal of Sport Nutrition, Vol. 6 No 4, pp. 391-401.

Beals, K. A., Hill, A. K. (2006). The prevalence of disordered eating, menstrual dysfunction, and low bone mineral density among US collegiate athletes. International Journal of Sport Nutrition and Exercise Metabolism, Vol. 16 No. 1, pp. 1-23.

Byrne, S., McLean, N. (2002), Elite athletes: Effects of the pressure to be thin. Journal of Science \& Medicine in Sport, Vol. 5 No 2, pp. 80-94.

De Souza, M. J, Nattiv, A., Joy, E., et al. (2014), 2014 Female Athlete Triad Coalition Consensus Statement on Treatment and Return to Play of the Female Athlete Triad: 1st International Conference held in San Francisco, California, May 2012 and 2nd International Conference held in Indianapolis, Indiana, May 2013. British Journal of Sports Medicine Vol. 48 No4, pp. 289.

Fairburn, C. G., Beglin, S. J. (2008). Eating Disorder Examination Questionnaire (EDE-Q 6.0). In C. G. Fairburn (Ed.), Cognitive behavior therapy and eating disorders (pp. 309-313). New York: Guilford Press.

Harris, M.B., Greco D. (1990) Weight control and weight concern in competitive female gymnasts. Journal of Sport and Exercise Psychology, Vol. 12 No 4, pp. 427-433.

Johnson, C., Powers, P.S., Dick, R. (1999)
Athletes and eating disorders: The National Collegiate Athletic Association study. International Journal of Eating Disorders, Vol. 26 No 2, pp. 179-188.

Lavender, J.M., de Young, K.P., Anderson, D.A. (2010) Eating Disorder Examination Questionnaire (EDE-Q): norms for undergraduate men. Eating Behavior, Vol. 11 No.2, pp. 119-121.

Luce, K.H., Crowther, J.H., Pole, M. (2008) Eating Disorder Examination Questionnaire (EDEQ): norms for undergraduate women. International Journal of Eating Disorders, Vol. 41 No 3, pp. 273-276.

Martinsen, M., Bratland-Sanda, S., Eriksson, A. K., Sundgot-Borgen, J. (2010). Dieting to win or to be thin? A study of dieting and disordered eating among adolescent elite athletes and non-athlete controls. British Journal of Sports Medicine, Vol. 44 No1, pp.70-76.

Mond, J.M., Myers, T.C., Crosby, R.D. et al. (2008) Screening for eating disorders in primary care: EDE-Q versus SCOFF. Behavior Research Therapy, Vol. 46 No 5, pp. 612-622.

Nichols, J. F., Rauh, M. J., Barrack, M. T., Barkai, H. S., Pernick, Y. (2007), Disordered eating and menstrual irregularity in high school athletes in lean-build and nonlean-build sports. International Journal of Sport Nutrition and Exercise Metabolism, Vol. 17 No 4, pp. 364-377.

Nichols, J. F., Rauh, M. J., Lawson, M. J., Ji, M., Barkai, H. S. (2006), Prevalence of the female athlete triad syndrome among high school athletes. Archives of Pediatric Adolescence Medicine, Vol. 160 No 2, pp. 137-142.

Pernick, Y., Nichols, J. F., Rauh, M. J., et al. (2006) Disordered eating among a multiracial/ethnic sample of female high-school athletes. Journal of Adolescence Health, Vol. 38 No 6, pp. 689-695.

Petrova S., Zyumbyuleva Zh., Duleva V., Rangelova L., Bozhilova D. Hranitelno povedenie na naselenieto $\mathrm{v}$ Balgaria na vazrast ot 10 do 40 godini. Nacionalen Centar po 
Obshtestveno Zdrave I Analizi, available at: http://ncphp.government.bg/files/news/flash/ Slide8.swf (accessed 14 September 2017).

Picard, C.I. (1999) The Level of Competition as a Factor for the Development of Eating Disorders in Female Collegiate Athletes. Journal of Youth and Adolescents, Vol. 28 No 5, pp. 583-594.

Reinking, M. Alexander, L. (2005) Prevalence of Disordered-Eating Behaviors in Undergraduate Female Collegiate Athletes and Nonathletes. Journal of Athletic Training, Vol. 40 No 1, pp. 47-51.

Rosen, L.W., Hough, D.O. (1988) Pathogenic weight-control behaviors of female college gymnasts. Physician and Sportsmedicine, Vol. 16, No 9, pp. 141-144.

Rosendahl, J., Bormann, B., Aschenbrenner, K., Aschenbrenner, F., \& Strauss, B. (2009). Dieting and disordered eating in German high school athletes and non-athletes. Scandinavian Journal of Medicine \& Science in Sports, Vol. 19 No 5, pp. 731-739.

Smolak, L., Murnen, S.K., Ruble, A.E. Female athletes and eating problems: a metaanalysis. International Journal of Eating Disorders, 2000; 27:371-380.

Sundgot-Borgen, J. (1993), Prevalence of eating disorders in elite female athletes. International Journal of Sport Nutrition, Vol. 3 No 1, pp. 29-40.

Sundgot-Borgen, J. (1994) Risk and trigger factors for the development of eating disorders in female elite athletes. Medicine and Science in Sport and Exercise, Vol. 26 No 4, pp. 414-419.

Sundgot-Borgen, J. (1996) Eating disor- ders, energy intake, training volume, and menstrual function in high-level modern rhythmic gymnasts. International Journal of Sport Nutrition, Vol. 6 No 2, pp. 100-109.

Sundgot-Borgen, J., Corbin, C.B. (1987) Eating disorders among female athletes. Physician Sportsmedicine, Vol. 15, No 2, pp. 8995.

Sundgot-Borgen, J., S. Larsen (1993) Pathogenic weight-control methods and selfreported eating disorders in female elite athletes and controls. Scandinavian Journal of Medicine \& Science in Sport and Exercise, Vol. 3 No 3, pp.150-155.

Thompson, S. H., Gabriel, M. (2004). Risk factors for the female athlete triad among female collegiate and noncollegiate athletes. Physical Education, Vol. 61 No.4, pp. 200212.

Torstveit, M. K., Rosenvinge, J. H., \& Sundgot-Borgen, J. (2008). Prevalence of eating disorders and the predictive power of risk models in female elite athletes: A controlled study. Scandinavian Journal of Medicine \& Science in Sports, Vol. 18 No1, pp. 108-118.

Welch, E., Birgegård, A., Parling, T., \& Ghaderi, A. (2011). Eating Disorder Examination Questionnaire and clinical impairment assessment questionnaire: General population and clinical norms for young adult women in Sweden. Behaviour Research and Therapy, Vol.49, No 2, pp. 85-91.

West, R.V. (1998) The female athlete: the triad of disordered eating, amenorrhoea and osteoporosis. Sports Medicine, Vol. 26 No 2, pp. 63-71.

\section{Correspondence:}

Diana Dimitrova

National Sports Academy "Vassil Levski" Department "Sports medicine" Studentski grad, 21, Acad. Stefan Mladenov Str.

Sofia 1700, Bulgaria E-mail: dianansa@yahoo.com 